\title{
Exercise training improves erectile dysfunction (ED) in patients with metabolic syndrome on phosphodiesterase-5 (PDE-5) inhibitors
}

\section{L'esercizio fisico migliora il grado di disfunzione erettile (ED) nei pazienti con sindrome metabolica in terapia con inibitori della fosfodiesterasi-5 (PDE-5)}

\author{
Luigi Maresca1, ${ }^{*}$, Mariantonietta D’Agostino1, ${ }^{*}$, Luigi Castaldo3, Alessandra Vitelli1, \\ Maria Mancini1, Giorgio Torella1, Rosa Lucci1,Giovanna Albano1, Domenico Del Forno2, \\ Matteo Ferro3, Vincenzo Altieri3, Francesco Giallauria1,4, Carlo Vigorito1
}

\begin{abstract}
Exercise training improves erectile dysfunction (ED) in patients with metabolic syndrome on phosphodiesterase-5 (PDE-5) inhibitors. L. Maresca, M. D'Agostino, L. Castaldo, A. Vitelli, M. Mancini, G. Torella, R. Lucci, G. Albano, D. Del Forno, M. Ferro, V. Altieri, F. Giallauria, C. Vigorito.

Introduction. Erectile dysfunction (ED) affects about $50 \%$ of males aged 40-70 years old. ED shares with atherosclerotic disease several common risk factors; therefore, it may be considered a surrogate marker of atherosclerosis. Sincephosphodiesterase-5 inhibitors are well known pharmacologic agents capable of significant improvement in ED, we designed this study to evaluate whether exercise training is of added value in patients with ED who are already on PDE-5 inhibitors.

Methods. We recruited 20 male patients affected by ED with metabolic syndrome.At baseline, all patients underwent Cardio-Pulmonary Exercise Testing (CPET) and the International Index of Erectile Function (IIEF) test.After the initial evaluation, patients were subdivided into two groups: tadalafil group (group $\mathrm{T}, \mathrm{n}=10$ ), who were maintained only on tadalafil therapy, and a tadalafil/exercise
\end{abstract}

training group $(\mathrm{T} / \mathrm{E}$ group, $\mathrm{n}=10)$ who continued tadalafil but in addition underwent a2-month structured exercise training program.

Results. Basal anthropometric characteristics of study population showed no significant differences. Although bothgroups showed at 2 months an improvement of the IIEF score, thiswas more evident in the $\mathbf{T} / \mathbf{E}$ group (T group: 11.2 vs $\mathbf{1 4 . 2}, \mathrm{P}=\mathbf{0 . 0 2}$; $\mathrm{T} / \mathrm{E}$ group: $\mathbf{1 0 . 8}$ vs $\mathbf{2 0 . 1}, \mathrm{P}<\mathbf{0 . 0 0 1})$. There was an improvement of oxygen consumption at peak exercise $\left(\mathrm{VO}_{2 \text { peak }}\right.$ ) only in the $\mathrm{T} / \mathrm{E}$ group patients ( $\mathrm{T}$ group: $13.63 \pm 2.03$ vs $14.24 \pm 2.98 \mathrm{~mL} / \mathrm{kg} / \mathrm{min} ; P=0.521 ; T / E$ group: $13.41 \pm 2.97$ vs $16.58 \pm 3.17 \mathrm{~mL} / \mathrm{kg} / \mathrm{min} ; P=0.006)$. A significant correlation was found between the changes in $\mathrm{VO}_{2 \text { peak }}$ and the modifications in IIEF score $(r=0.575 ; P=0.001)$.

Conclusion. Exercise training in ED patients treated with PDE-5 inhibitors is of added valuesincefurther improves ED, as evaluated by IIEF score, and increases functional capacity.

Keywords: erectile dysfunction, exercise training, metabolic syndrome, phosphodiesterase-5, erectile dysfunction therapy.

Monaldi Arch Chest Dis 2013; 80: 177-183.

\footnotetext{
* Both Authors contributed equally to this work.

I Department of Translational Medical Sciences, University of Naples Federico II, Naples, Italy.

2 Department of Advanced Biomedical Sciences, University of Naples Federico II, Naples, Italy.

3 Department ofMedicine and Surgery, University of Salerno Medical School, Salerno, Italy.

${ }_{4}$ School of Science and Technology, University of New England, Armidale, NSW 2351, Australia.
}

Corresponding author: Luigi Maresca, M.D.; Cardiac Rehabilitation Unit, University of Naples "Federico II"; via Pansini 5, I-8013I Naples (Italy); E-mail address: luigimaresca@alice.it

\section{Introduction}

Erectile dysfunction (ED) affects about $50 \%$ of males aged 40-70 years old, and is in this age range one of the most important aspectaffecting quality of life [1]. ED shares with atherosclerotic disease several common risk factors, such as hypertension, hypercholesterolemia, obesity or sedentary habits, diabetes and cigarette smoking [2-5]; therefore, ED is a surrogate marker of atherosclerotic disease [6]. Phosphodiesterase-5 inhibitorsare well known pharmacologic agents ca- pable of significant improvement in ED [7]. Recent studies, including some small randomized controlled trials and one meta-analysis [8] have demonstrated that alsolife-style changes, including exercise and/or diet, alone or in combination, have a favorable effect on ED and cardiovascular riskfactors in patients with ED and impairedcardiovascular risk profile [8-11]. In particular, exercise training, alone or as core component of cardiac rehabilitation programs, exerts beneficial effects on cardiovascular system, including an improvement in vascular endothelial function [12-14], 
global atherosclerotic risk profile [15], beta-receptor signaling [16, 17], free radical expression [18], inflammation [19], cardiovascular functional capacity [20-24] and other several cardiovascular outcomes $[25,26]$. However, only 2 studies analyzed separately the effect of an exercise intervention on ED in patients with obesity [9] or hypertension [11], both showing significant although modest improvement in ED.Moreover, in none of these studies the studypatient population was on therapy with PDE-5 Inhibitors. Hence, the potential additive effects of exercise training in patients with ED who arealready on PDE-5 inhibitors are still unknown.Therefore, in this study we evaluated whether exercise training is capable of a further improvement in ED in patients who are already on PDE-5 inhibitors.

\section{Methods}

\section{Study population and protocol}

Twenty male patients affected by ED andmetabolic syndromeaddressed to a firstout-patient evaluation at the urological ambulatory (age $68.5 \pm 3.2$ years)were enrolled into the study. Exclusion criteria were: inducible ischemia at the routine stress testing, previous cardiovascular event, known coronary artery disease ornon-organic ED (psychogenic, iatrogenic, etc.). At baseline, all patients underwent Cardio-Pulmonary Exercise Test (CPET) and International Index of Erectile Function (IIEF) test, a validated test for the evaluation of ED [27]. Tadalafil $5 \mathrm{mg} /$ die (Cialis ${ }^{\circledR}$; Eli Lilly, Indianapolis, Indiana, USA) was administeredfor treating ED at patient enrollment. After the initial evaluation, patients were subdividedinto two groups: a $\mathrm{T}$ group ( $\mathrm{n}=10$ patients) was treated with tadalafil $5 \mathrm{mg} / \mathrm{die}$ (Control Group), whereas a $\mathrm{T} / \mathrm{E}$ group $(\mathrm{n}=10$ patients $)$ was treated with tadalafil $5 \mathrm{mg} /$ die and was enrolled in a 2 -month structured exercise training program (Training Group). Demographic and cardiovascular risk profiles of the study populationwere given in Table 1: there were no significant differences between the two groups at baseline.According to the 2005 AHA/NHLBI scientific statement, all patients satisfied the diagnostic criteria for metabolic syndrome [28]. Structured exercise training programwas carried out on a hospital outpatient-based regimen. The training program consisted on 3 exercise sessions per week under continuous electrocardiographic monitoring and undersupervisionof a cardiologist and a physiotherapist. Each session was preceded by a 5-min warm-up and followed by a 5-min cool-down. Exercise was performed for 30 min on a bicycle ergometer or on a treadmill with the heart rate target of $65 \%$ of the maximal oxygen consumption $\left(\mathrm{VO}_{2 \text { peak }}\right)$ achieved at the initial cardiopulmonary exercise test. The heart rate was monitored by a wearable device. Exercise workload was gradually increased until the achievement of the predefined target. The T group received only generic information on the usefulness of exercise. After 2 months, all patients repeatedthe CPET and the IIEF.

\section{Cardiopulmonary Exercise Test (CPET)}

All patients performed an incremental wattramp symptom-limited cardiopulmonary exercise test protocol on a bicycle ergometer. Before each test, oxygen and carbon dioxide analyzers and a flow mass sensor were calibrated by use of available precision gas mixtures and a 3-liter syringe, respectively. To stabilize gas measurements, patients were asked to remain still on the ergometer for at least $3 \mathrm{~min}$ before starting exercise. After1-min warm-up period at 0 Watt workload, a ramp protocol of $15 \mathrm{Watt} / \mathrm{min}$ was started and continued until exhaustion. The pedaling was kept constant at 55-65 revolutions per minute. A 12-lead electrocardiogram was monitored continuously during the test, and arm blood pressure was manually recorded every 2 min. Respiratory gas exchange measurements, that is minute ventilation (VE), oxygen consumption $\left(\mathrm{VO}_{2}\right)$ and carbon dioxide production $\left(\mathrm{VCO}_{2}\right)$, were obtained breath by breath with the

Table 1. - Demographic and cardiovascular risk profile of the study population

\begin{tabular}{|c|c|c|c|c|}
\hline & $\begin{array}{c}\text { Total } \\
\text { Population } \\
(\mathbf{n}=\mathbf{2 0})\end{array}$ & $\begin{array}{c}\text { Tadalafil } \\
\text { Group } \\
(\mathbf{n}=\mathbf{1 0})\end{array}$ & $\begin{array}{c}\text { Tadalafil + Exercise } \\
\text { Training Group } \\
\quad(\mathbf{n}=\mathbf{1 0})\end{array}$ & $\begin{array}{c}P \text { value } \\
\text { (between } \\
\text { groups }\end{array}$ \\
\hline Age (years) & $68.5 \pm 3.2$ & $68.0 \pm 3.6$ & $69.0 \pm 2.8$ & 0.498 \\
\hline Systolic Blood Pressure (mmHg) & $138.7 \pm 4.1$ & $139.5 \pm 4.4$ & $137.9 \pm 3.9$ & 0.401 \\
\hline Diastolic Blood Pressure (mmHg) & $90.7 \pm 5.5$ & $90.0 \pm 5.3$ & $91.4 \pm 5.8$ & 0.580 \\
\hline Glycemia (mg/dL) & $107.0 \pm 7.9$ & $107.8 \pm 8.5$ & $106.1 \pm 7.5$ & 0.641 \\
\hline Total Cholesterol (mg/dL) & $214.5 \pm 21.3$ & $212.2 \pm 21.6$ & $216.8 \pm 21.9$ & 0.641 \\
\hline LDL Cholesterol (mg/dL) & $145.4 \pm 21.2$ & $143.1 \pm 21.0$ & $147.7 \pm 22.2$ & 0.634 \\
\hline HDL Cholesterol (mg/dL) & $32.9 \pm 4.7$ & $32.8 \pm 5.1$ & $32.9 \pm 4.5$ & 0.963 \\
\hline Triglycerides (mg/dL) & $181.3 \pm 16.6$ & $181.7 \pm 19.1$ & $180.8 \pm 14.8$ & 0.908 \\
\hline Waist circumference $(\mathrm{cm})$ & $103.2 \pm 3.8$ & $102.5 \pm 3.6$ & $103.9 \pm 4.0$ & 0.418 \\
\hline
\end{tabular}


use of a computerized metabolic cart (Vmax 29C; Sensormedics, Yorba Linda, California). $\mathrm{VO}_{2 \text { peak }}$ was recorded as the mean of $\mathrm{VO}_{2}$ during the last 20 $\mathrm{sec}$ of the test, evidenced by a failure for $\mathrm{VO} 2$ to increase further despite an increase in work rate, and was expressed in millimeters per kilogram per minute. At the end of the cardiopulmonary exercise test, patients were asked to identify the primary reason for stopping. Peakoxygen consumption $\left(\mathrm{VO}_{2 \text { peak }}\right)$ and oxygen consumption at anaerobic threshold $\left(\mathrm{VO}_{2 \mathrm{AT}}\right)$ were measured and compared with maximal predicted $\mathrm{VO}_{2}$ by use of a sex-, age-, height-, and weight-adjusted and protocol specific formula; and ventilatory anaerobic threshold (AT) was detected by use of the V-slope methodas detailed elsewhere $[29,30]$. The VE $v s . \mathrm{VCO}_{2}$ relationship was measured by plotting VE against $\mathrm{VCO}_{2}$ obtained every $10 \mathrm{sec}$ of exercise $\left(\mathrm{VE} / \mathrm{VCO}_{2 \text { slope }}\right)$; both $\mathrm{VE}$ and $\mathrm{VCO} 2$ were measured in liters per minute. The $\mathrm{VE} / \mathrm{VCO}_{2 \text { slope }}$ was calculated as a linear regression function, excluding the nonlinear part of the relationship after the onset of acidotic drive to ventilation.

\section{International Index of Erectile Function (IIEF)}

The International Index of Erectile Function test represents an efficient and useful tool for the multidimensional assessment of the sexual function in male population [27]. In 1999it was recommended as a primary endpoint by the "First International Consultation on Erectile Dysfunction" and sponsored by the World Health Organization for the diagnostic evaluation of ED. It consists of a validated and reliable 15 -item questionnaire that is self-administered by the patient himself. It addresses the relevant domains of male sexual function (that is, erectile function, orgasmic function, sexual desire, intercourse satisfaction, and overall satisfaction), is psychometrically sound, and has been linguistically validated in 32 languages. Erectile function is explored by the questions $1,2,3,4$, 5 and 15 , with an overall score of 30 . These questions are able to quantify the degree of erectile dysfunction, which may be classified as: severe (6-10 score), moderate (11-16), mild (17-25) or normal (26-30) (see Table 2).

\section{Statistical analysis}

Data are expressed as percentages for discrete variables and mean \pm standard deviation for continuous variables. Comparisons between groups at randomization were performed by unpaired t test,

\begin{tabular}{|c|c|}
\hline IIEF Test Score & ED Classification \\
\hline $6-10$ & SEVERE \\
\hline $11-16$ & MODERATE \\
\hline $17-25$ & MILD \\
\hline $26-30$ & ABSENCE OF ED \\
\hline
\end{tabular}

$\chi^{2}$ or Fisher's exact test as required. The distribution of continuous variables was analyzed by Kolmogorov-Smirnov test of normality. The comparison between the control and the experimental group in biochemical and ventilatory function data was performed by the Student's $t$ test for paired data. The bivariate correlations procedure was used to compute Pearson'sor Spearman's correlation coefficients. A $p$ value $<0.05$ was considered statistically significant. All statistical analyses were performed using the software package SPSS, version 15.0 (SPSS Inc., Chicago, IL, USA).

\section{Results}

The results of CPET and of the IIEF are shown in Table 3. Both groups showed an improvement of the IIEF score: groupT remained within the moderate degree ED score (11.2 vs 14.2 score, $P=0.02$ ); whereas group $\mathrm{T} / \mathrm{E}$, undergoing 2 monthsmedical therapy plus exercise training showed a significant improvement in IIEF score shifting from a basal moderate ED to a mild impairment (10.8 vs 20.1 score, $P<0.0001$ ) (Fig. 1 and Table 3). Furthermore, the percentage enhancement of the IIEF score was $40 \%$ in the $\mathrm{T}$ group and $100 \%$ in the T/E group, revealing a statistically significant difference between the two groups at the end of the 2 months treatment $(p<0.001$ between the 2 groups at 2-months results).The improvement of oxygen consumption at peak exercise $\left(\mathrm{VO}_{2 \text { peak }}\right)$ was statistically significant only in the T/E group patients $\left(\mathrm{VO}_{2 \text { peak }}=13.41 \pm\right.$ 2.97 vs $16.58 \pm 3.17 \mathrm{~mL} / \mathrm{kg} / \mathrm{min} ; P=0.006)$; whereas in the $\mathrm{T}$ group (controls) the $\mathrm{VO}_{2 \text { peak }}$ improvement was not significant $\left(\mathrm{VO}_{2 \text { peak }}=13.63 \pm\right.$ 2.03 vs $14.24 \pm 2.98 \mathrm{~mL} / \mathrm{kg} / \mathrm{min} ; P=0.521)$. In addition, in the entire study population, a significant positive correlation $(r=0.574 ; P=0.001$; Fig. 2) was found between $\Delta \mathrm{VO}_{2 \text { peak }}$ and $\Delta \mathrm{IIEF}$. However, after 2 months, T/E group patients did notshowa significant improvement of the metabolic risk profile (Table 4).

Table 3. - CPET and IIEF test results

\begin{tabular}{lcc}
\hline & $\begin{array}{c}\text { Tadalafil } \\
\text { group } \\
(\mathbf{n}=\mathbf{1 0})\end{array}$ & $\begin{array}{c}\text { Tadalafil + exercise } \\
\text { training group } \\
(\mathbf{n}=\mathbf{1 0})\end{array}$ \\
\hline $\begin{array}{l}\mathrm{VO} 2 \mathrm{peak} \\
(\mathrm{Basal} ; \mathrm{mL} / \mathrm{kg} / \mathrm{min})\end{array}$ & $13.63 \pm 2.03$ & $13.41 \pm 2.97$ \\
\hline $\begin{array}{l}\text { VO2peak } \\
(\text { After } 2 \text { months; } \\
\mathrm{mL} / \mathrm{kg} / \mathrm{min})\end{array}$ & $14.24 \pm 2.98$ & $16.58 \pm 3.17$ \\
\hline$P$ value & 0.521 & 0.006 \\
\hline & & \\
\hline $\begin{array}{l}\text { IIEF Test Score } \\
(\text { Basal })\end{array}$ & $11.2 \pm 2.1$ & $10.8 \pm 2.0$ \\
\hline $\begin{array}{l}\text { IIEF Test Score } \\
\text { (After 2 months })\end{array}$ & $14.2 \pm 2.2$ & $20.1 \pm 2.3$ \\
\hline$P$ value & 0.01660 & $<0.00001$ \\
\hline
\end{tabular}




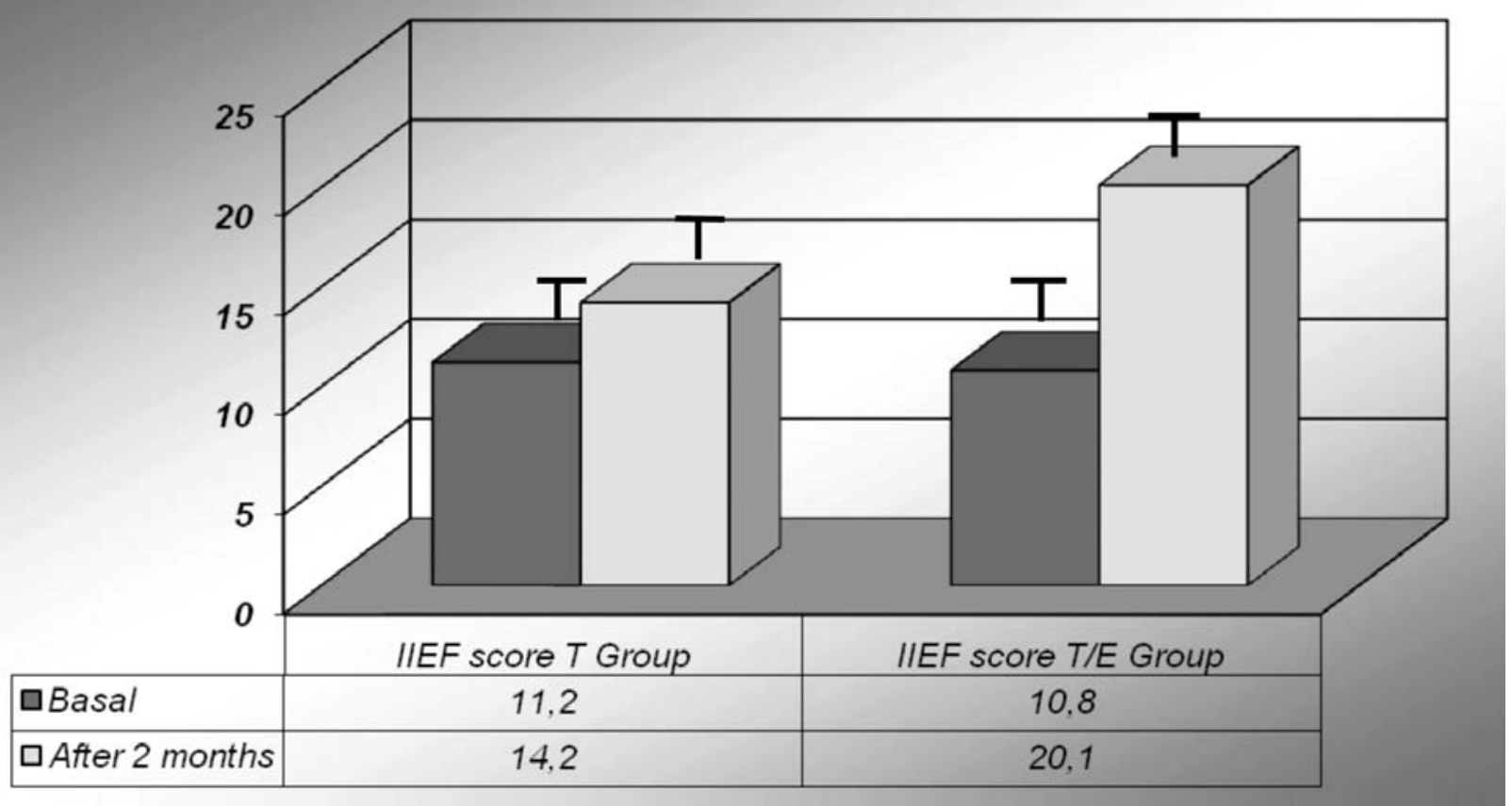

Figure 1. - IIEF Test Score in both Groups (T group: $\mathrm{P}=0.01660$; T/E group: $\mathrm{P}<0.00001$ ).

(T Group: $\quad$ basal: $11.2 \pm 2.1 \quad 2$ th month: $14.2 \pm 2.2$ )

(T/E Group: basal: $10.8 \pm 2.0 \quad$ 2th month: $20.1 \pm 2.3$ )

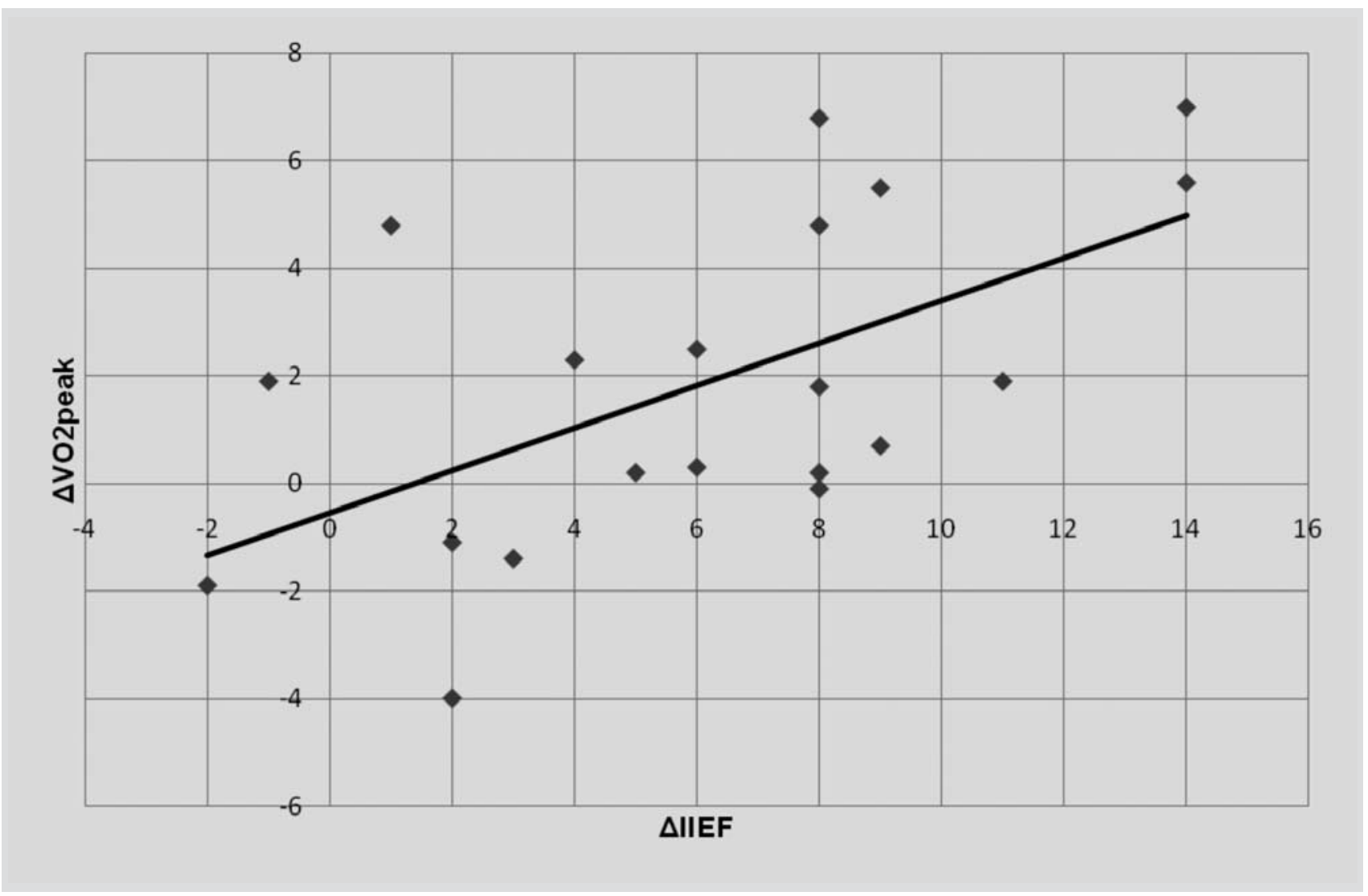

Figure 2. - Correlation between changes in DIIEF score (x) vs. changes in DVO2peak(y) in the entire study population(n=20; $r=0.575$; $P=0.001)$.

\section{Discussion}

The most important observation of our study was that, in addition to the expected improvement of ED in patients on Tadalafil only, the improvement of the ED was markedly increased in patients who practiced exercise training and were already on Tadalafil therapy. Indeed, the IIEF test significantly improved in the $\mathrm{T} / \mathrm{E}$ group patientscompared to the $\mathrm{T}$ group. The association between the implementation of a training program and the improvement of the erectile function in this patient population is 
Table 4. - Cardiovascular risk profile at baseline and after 2 months

\begin{tabular}{|c|c|c|c|c|c|c|}
\hline & $\begin{array}{l}\text { Tadalafil } \\
\text { Group } \\
\text { (Baseline) }\end{array}$ & $\begin{array}{c}\text { Tadalafil } \\
\text { Group } \\
\text { (After } 2 \text { months) }\end{array}$ & $P$ Value & $\begin{array}{c}\text { Tadalafil + Exercise } \\
\text { Training Group } \\
\text { (Baseline) }\end{array}$ & $\begin{array}{l}\text { Tadalafil + Exercise } \\
\text { Training Group } \\
\text { (After } 2 \text { months) }\end{array}$ & $P$ Value \\
\hline $\begin{array}{l}\text { Systolic Blood } \\
\text { Pressure }(\mathrm{mmHg})\end{array}$ & $139.5 \pm 4.4$ & $137.5 \pm 5.0$ & 0.141 & $137.9 \pm 3.9$ & $136.0 \pm 4.1$ & 0.184 \\
\hline $\begin{array}{l}\text { Diastolic Blood } \\
\text { Pressure }(\mathrm{mmHg})\end{array}$ & $90.0 \pm 5.3$ & $87.8 \pm 6.2$ & 0.211 & $91.4 \pm 5.8$ & $89.5 \pm 6.0$ & 0.076 \\
\hline $\begin{array}{l}\text { Glycemia } \\
(\mathrm{mg} / \mathrm{dL})\end{array}$ & $107.8 \pm 8.5$ & $108.9 \pm 9.6$ & 0.712 & $106.1 \pm 7.5$ & $104.7 \pm 6.4$ & 0.618 \\
\hline $\begin{array}{l}\text { Total Cholesterol } \\
(\mathrm{mg} / \mathrm{dL})\end{array}$ & $212.2 \pm 21.6$ & $208.2 \pm 26.0$ & 0.558 & $216.8 \pm 21.9$ & $210.9 \pm 20.3$ & 0.206 \\
\hline $\begin{array}{l}\text { LDL Cholesterol } \\
(\mathrm{mg} / \mathrm{dL})\end{array}$ & $143.1 \pm 21.0$ & $136.8 \pm 26.5$ & 0.412 & $147.7 \pm 22.2$ & $143.5 \pm 19.5$ & 0.367 \\
\hline $\begin{array}{l}\text { HDL Cholesterol } \\
(\mathrm{mg} / \mathrm{dL})\end{array}$ & $32.8 \pm 5.1$ & $32.7 \pm 5.9$ & 0.868 & $32.9 \pm 4.5$ & $33.9 \pm 4.0$ & 0.317 \\
\hline $\begin{array}{l}\text { Triglycerides } \\
(\mathrm{mg} / \mathrm{dL})\end{array}$ & $181.7 \pm 19.1$ & $193.5 \pm 23.8$ & 0.168 & $180.8 \pm 14.8$ & $177.7 \pm 19.4$ & 0.545 \\
\hline $\begin{array}{l}\text { Waist circumference } \\
(\mathrm{cm})\end{array}$ & $102.5 \pm 3.6$ & $103.4 \pm 4.1$ & 0.487 & $103.9 \pm 4.0$ & $103.3 \pm 4.3$ & 0.217 \\
\hline
\end{tabular}

also suggested by the significant correlationamong the changes in IIEF test score and in the $\mathrm{VO}_{2 \text { peak }}$ in the $\mathrm{T} / \mathrm{E}$ group after two months of exercise training. At the present, there are not literature clarifying the mechanism(s) of the additional benefit of exercise training on the erectile dysfunction in patients already on PDE-5 inhibitors therapy. In the metaanalysis by Gupta et al. [8], showing a beneficial effect of life style changes on ED, only 2 of the included studies analyzed separately the effect of an exercise intervention only on ED in patients with obesity [9] or hypertension [11], both showing only modest improvement in ED. However, in none of these studies the included patient population was on PDE-5 inhibitors. Therefore, we could not exclude that the beneficial effect of exercise training in these two studies would not be observed in other patients already on PDE-5 inhibitors. On the opposite, in our patients we foundan incremental value of exercise training on EDimprovement. Interestingly, the mean increment in IIEF score of 4.0 with exercise in the paperby Esposito et al. [31] and of 3.6 in the paperby Lamina et al. [11] are similar to the additional value of 5.9 observed in our study as the added value of exercise training on ED score in our patients assuming tadalafil. To this regard, it must be underscored that only the association of tadalafil and exercise training increased the IIEF score in our patients with baseline moderate ED by a value (mean 9.3 increment) to be considered as clinically relevant (i.e. 5 points improvement in IIEF score) [32], while the mean score increase of3.0 in the tadalafil group was not sufficient to achieve this goal.Therefore, our study underlines that the synergic action of a structured program of exercise training added to the pharmacological therapy with tadalafil in patients with a chronic moder- ate ED could amplify the pharmacological effect of the PDE-5 inhibitor. This magnified effect could improve ED up toclinical relevant values.

In addition to the effects on ED, exercise training also induced a global improvement in functional capacity, expressed as an increase of the oxygen consumption at peak exercise $\left(\mathrm{VO}_{2 \text { peak }}\right)$, which represents a strong prognostic predictor of cardiovascular disease and death [33], in this case not accompanied by an improvement of the cardiovascular risk profile, probably due to the very small number of study patients. The mechanisms underlying the favourable effects of exercise training include an improvement of vascular endothelial function, a reduction of peripheral resistances and an increase of the $\mathrm{O}_{2}$ consumption by the peripheral muscles [13]. The significant correlation found between exerciseinduced changes in IIEF score and in $\mathrm{VO}_{2 \text { peak }}$ suggests that common mechanisms, such as an improvement in vascular endothelial function, are at the base of the favorable improvement of these parameters.In fact, ED represents an early sign of endothelial dysfunction and arterial stiffness [34]. The PDE-5 inhibitors are pharmacological agents able to augment the NO/cGMP pathway and to determine dilationof the smooth muscle [37]. Previously, the peripheral vasodilatation mediated by the action of PDE-5 inhibitorshas been identified as the main factor enhancing $\mathrm{VO}_{2 \text { peak }}$ in patients with chronic heart failure [38, 39]. and in patients with metabolic syndrome [40]. However, as in our study tadalafil alone did not led to a significant increase of the $\mathrm{VO}_{2 \text { peak }}$, we suggest that the pharmacological effect of the PDE-5 inhibitors on this essential functional parameter is particularly evident in chronic heart failure patients, who present a severe compromise ofsystemic and pulmonary hemodynamicsand of en- 
dothelial function. On the contrary, in patients with metabolic syndrome and without cardiovascular structural disease, such as those included in our study, $\mathrm{VO}_{2 \text { peak }}$ was not significantly affected by PDE-5 inhibitors. In this patient population exercise training becomes of remarkable importance in improving cardiovascular capacity.

\section{Conclusions}

Structured exercise training in patients with ED and on PDE-inhibitors is of added valuefor improvingED compared to PDE-5 inhibitors therapy alone. Future trialsare mandatory in order to confirm the additional benefits of exercise training in a largerED population and to establish the global benefit of these programs in ED patient.

Author's contributions: CV, FG and VA designed the study. MD, LC, RL, MF and GT performed the CPET and the IIEF test.LM, DDF, GA and MM collected the data. LM, AV and MM took blood samples. LM, MD and FG analyzed the data. $\mathrm{LM}, \mathrm{MD}$ and $\mathrm{CV}$ prepared the manuscript. CV and VA gave suggestions for this work. We thank Mr. Mario Aurino for his technical support during the training programs.

\section{References}

1. Ayta IA, McKinlay JB, Krane RJ. The likely World-Wide increase in erectile dysfunction between 1995 and 2025 and some possible policy consequences. BJU Int 1999; 84 (1): $50-56$

2. Grover SA, Lowensteyn I, Kaouache M, et al. The prevalence of erectile dysfunction in the primary care setting: importance of risk factors for diabetes and vascular disease. Arch Intern Med 2006; 166 (2): 213-219.

3. Kupelian V, Link CL, McKinlay JB. Association between smoking, passive smoking, and erectile dysfunction: result from the Boston Area Community Health (BACH) Survey. Eur Urol 2007; 52 (2): 416-422.

4. Gades NM, Nehra A, Jacobson DJ, et al. Association between smoking and erectile dysfunction: a populationbased study. Am J Epidemiol 2005; 161 (3): 346-351.

5. Ma RC, So WY, Yang X, et al. Erectile dysfunction predicts coronary heart disease in type 2 diabetes. $J$ Am Coll Cardiol 2008; 51 (21): 2045-2050.

6. Araujo AB, Hall SA, Ganz P, et al. Does erectile dysfunction contribute to cardiovascular disease risk prediction beyond the Framingham risk score? J Am Coll Cardiol 2010; 55 (4): 350-355.

7. Tsertsvadze A, Fink HA, Yazdi F, et al. Oral Phosphodiesterase-5 inhibitors and hormonal treatments for erectile dysfunction: a systematic review and meta-analysis. Arch Intern Med 2009; 151 (9): 650-661.

8. Gupta BP, Murad MH, Clifton MM, Prokop L, Nehra A, Kopecky SL. The effect of lifestyle modification and cardiovascular risk factor reduction on erectile dysfunction: a systematic review and meta-analysis. Arch Intern Med 2011; 171 (20): 1797-803.

9. Esposito K, Ciotola M, Giugliano F, et al. Mediterranean Diet improves erectile function in subjects with the metabolic syndrome. Int J Impot Res 2006; 18 (4): 405-410.

10. Wing RR, Rosen RC, Fava JL, et al. Effects of weight loss intervention on erectile function in older men with type 2 diabetes in the Look AHEAD trial. $J$ Sex Med 2010; 7 (1, Pt 1): 156-165.

11. Lamina S, Okoye CG, Dagogo TT. Therapeutic effect of an interval exercise training program in the management of erectile dysfunction in hypertensive patients. J Clin Hypertens (Greenwich) 2009; 11 (3): 125-129.
12. Vona M, Codeluppi GM, Iannino T, Ferrari E, Bogousslavsky J, von Segesser LK. Effects of different types of exercise training followed by detraining on endotheliumdependent dilation in patients with recent myocardial infarction. Circulation 2009; 119 (12): 1601-1608

13. Hambrecht R, Fiehn E, Weigl C, et al. Regular physical exercise corrects endothelial dysfunction and improves exercise capacity in patients with chronic heart failure. Circulation 1998; 98 (24): 2709-2715.

14. Indolfi $\mathrm{C}$, Torella $\mathrm{D}$, Coppola $\mathrm{C}$, et al. Physical training increases eNOS vascular expression and activity and reduces restenosis after balloon angioplasty or arterial stenting in rats. Circ Res 2002; 91 (12): 1190-1197.

15. Balducci S, Zanuso S, Nicolucci A, et al. Effect of an intensive exercise intervention strategy on modifiable cardiovascular risk factors in subjects with type 2 diabetes mellitus: a randomized controlled trial: the Italian Diabetes and Exercise Study (IDES). Arch Intern Med 2010; 170 (20): 1794-1803.

16. Leosco D, Rengo G, Iaccarino G, et al. Exercise promotes angiogenesis and improves beta-adrenergic receptor signaling in the post-ischaemic falling rat heart. Cardiovasc Res 2008; 78 (2): 385-394.

17. Leosco D, Rengo G, Iaccarino G, et al. Exercise training and beta-blocker treatment ameliorate age-dependent impairment of beta-adrenergic receptor signaling and enhance cardiac responsiveness to adrenergic stimulation. Am J Physiol Heart Circ Physiol 2007; 293 (3): H1596-603.

18. Rinaldi B, Corbi G, Boccuti S, et al. Exercise training affects age-induced changes in SOD and heat shock protein expression in rat heart. Exp Gerontol 2006; 41 (8): 764-770.

19. Giallauria F, Cirillo P, D'Agostino M, et al. Effects of exercise training on high-mobility group box-1 levels after acute myocardial infarction. J Card Fail 2011; 17 (2): 108-14.

20. Giallauria F, Lucci R, D'Agostino M, et al. Two-year multicomprehensive secondary prevention program: favorable effects on cardiovascular functional capacity and coronary risk profile after acute myocardial infarction. $J$ Cardiovasc Med (Hagerstown) 2009; 10 (10): 772-780.

21. Vigorito C, Giallauria F, Palomba S, et al. Beneficial effects of a three-month structured exercise training program on cardiopulmonary functional capacity in young women with polycistic ovary syndrome. J Clin Endocrinol Metab 2007; 92 (4): 1379-1384.

22. Giallauria F, Acampa W, Ricci F, et al. Effects of exercise training started within 2 weeks after acute myocardial infarction on myocardial perfusion and left ventricular function: a gated SPECT imaging study. Eur J Prev Cardiol 2012; 19(6): 1410-1419.

23. Giallauria F, Acampa W, Ricci F, et al. Exercise training early after acute myocardial infarction reduces stress-induced hypoperfusion and improves left ventricular function. Eur J Nucl Med Mol Imaging 2013; 40(3): 315-24.

24. Giallauria F, Galizia G, Lucci R, et al. Favourable effects of exercise-based Cardiac Rehabilitation after acute myocardial infarction on left atrial remodeling. Int J Cardiol 2009; 136 (3): 300-6

25. Leon AS, Franklin BA, Costa F, et al. Cardiac rehabilitation and secondary prevention of coronary heart disease: an American Heart Association scientific statement from the Council on Clinical Cardiology (Subcommittee on Exercise, Cardiac Rehabilitation, and Prevention) and the Council on Nutrition, Physical Activity, and Metabolism (Subcommittee on Physical Activity), in collaboration with the American association of Cardiovascular and Pulmonary Rehabilitation. Circulation 2005; 111: 369-76.

26. Smart NA, Meyer T, Butterfield JA, et al. Individual patient meta-analysis of exercise training effects on systemic brain natriuretic peptide expression in heart failure. Eur J Prev Cardiol 2012; 19 (3): 428-35. 
27. Rosen RC, Riley A, Wagner G,Osterloh IH, Kirkpatrick, Mishra A. The international index of erectile function (IIEF): a multidimensional scale for assessment of erectile dysfunction. Urology 1997; 49 (6): 822-830.

28. Grundy SM, Cleeman JI, Daniels SR, et al. Diagnosis and management of the metabolic syndrome: an American Heart Association/National Heart, Lung, and Blood Institute Scientific Statement. Circulation 2005; 112 (17): 2735-52.

29. Giallauria F, De Lorenzo A, Pilerci F, et al. Reductionof NT-pro-BNP Levels withExercise-BasedCardiac Rehabilitation in PatientswithLeftVentricularDysfunction after MyocardialInfarction. Eur J Cardiovasc Prev Rehabil 2006; 13(4): 625-632.

30. Giallauria F, Lucci R, Pietrosante M, et al. ExercisebasedCardiac Rehabilitation improves Heart Rate Recovery in ElderlyPatients after AcuteMyocardialInfarction. $J$ Gerontol Ser A - Biol Sci Med Sci 2006; 61(7): 713-717.

31. Esposito K, Giugliano F, Di Palo C, et al. Effect of lifestyle changes on erectile dysfunction in obese men: a randomized controlled trial. JAMA 2004; 291 (24): 2978-84.

32. Rosen RC, Allen KR, Ni X, Araujo AB. Minimal clinically important differences in the erectile function domain of the International Index of Erectile Function scale. Eur Urol 2011; 60 (5): 1010-6.

33. Parikh MN, Lund LH, Goda A, Mancini D. Usefulness of peak exercise oxygen consumption and the heart failure survival score to predict survival in patients $>65$ years of age with heart failure. Am J Cardiol 2009; 103 (7): 998-1002.
34. Chang ST, Chu CM, Hsu JT, et al. Scrutiny of cardiovascular risk factors by assessing arterial stiffness in erectile dysfunction patients. World J Urol 2010; 28 (5): 625-630.

35. Giallauria F, Ling SM, Schreiber C, et al. Arterial stiffness and bone demineralization: the Baltimore longitudinal study of aging. Am J Hypertens 2011; 24 (9): 970-5.

36. Giallauria F, Milaneschi Y, Tanaka T, et al. Arterial Stiffness and vitamin D levels: the Baltimore Longitudinal Study of Aging. J Clin Endocrinol Metab 2012; 97(10): 3717-23.

37. Schwarz ER, Kapur V, Rodriguez J, Rastogi S, Rosanio $\mathrm{S}$. The effects of chronic phosphodiesterase-5 inhibitor use on different organ systems. Int J Impot Res 2007; 19 (2): $139-48$.

38. Lewis GD, Shah R, Shahzad K, et al. Sildenafil improves exercise capacity and quality of life in patients with systolic heart failure and secondary pulmonary hypertension. Circulation 2007; 116 (14): 1555-62.

39. Guazzi M, Tumminello G, Di Marco F, Fiorentini C, Guazzi MD. The effects of phosphodiesterase-5 inhibition with sildenafil on pulmonary hemodynamics and diffusion capacity, exercise ventilatory efficiency, and oxygen uptake kinetics in chronic heart failure. $\mathrm{J}$ Am Coll Cardiol 2004; 44 (12): 2339-48.

40. Lugnier C. PDE inhibitors: a new approach to treat metabolic syndrome? Curr Opin Pharmacol 2011; 11 (6): 698-706.

41. Bozzetto L, Prinster A, Annuzzi G, et al. Liver fat is reduced by an isoenergetic MUFA diet in a controlled randomized study in type 2 diabetic patients. Diabetes Care 2012; 35 (7): 1429-35. 